\title{
Modulation of Binding Affinities between Foldamer-Based Anion Receptors and Chloride Ion ${ }^{\dagger}$
}

\author{
Jae-min Suk and Kyu-Sung Jeong* \\ Center for Bioactive Molecular Hybrids, Department of Chemistry, Yonsei University, Seoul 120-749, Korea \\ ${ }^{*}$ E-mail: ksjeong@yonsei.ac.kr \\ Received February 12, 2011, Accepted April 17, 2011
}

Key Words : Anion receptor, Foldamer, Indolocarbazole, Hydrogen bond

Synthetic receptors are a valuable tool to study noncovalent interactions between chemical species ranging from ions and small molecules to biomacromolecules such as proteins and nucleic acids. Most of the synthetic receptors prepared to date are cleft-type molecules or macrocycles that possess binding sites with convergent functional groups complementary to targets. ${ }^{1}$ The binding sites are in general preorganized by rigid covalent bonds in order to enhance the binding affinities. On the other hand, natural receptors such as proteins and enzymes contain binding pockets which are created by folding. A number of synthetic oligomers that fold like secondary structures of proteins have been prepared using small organic molecules. ${ }^{2}$ Upon folding, some of them afford an internal cavity that can accommodate ions and small organic molecules, thus serving as synthetic receptors. ${ }^{3}$

Our group has demonstrated that synthetic oligomers capable of folding in helical structures, called foldamers, can bind anions in an internal cavity by hydrogen bonds. ${ }^{4,5}$ For example, we prepared a series of oligoindole foldamers which consisted of biindolyl units connected by ethynyl linkers. ${ }^{4}$ Upon anion binding, the oligoindoles adopt helical structures as proven by various ${ }^{1} \mathrm{H}-\mathrm{NMR}$ techniques. We also used an indolocarbazole derivative for the construction of foldamer-based anion receptors. ${ }^{5}$ In particular, a watersoluble indolocarbazole trimer ${ }^{5 \mathrm{a}}$ was proven to bind small halides such as fluoride, chloride, and bromide with moderate affinities in $\mathrm{D}_{2} \mathrm{O}$ as determined by ${ }^{1} \mathrm{H}-\mathrm{NMR}$ titrations.

The foldamer-based anion receptors prepared in our group offer a tubular cavity templated by anion binding through hydrogen bonds. Maximum interactions between foldamers and anions depend on the complementarity of the contact areas of two interacting parts. As a result, each anion would have optimum dimension or height of the cavity which is determined by the length of oligomers. ${ }^{6}$ Herein, we investigated the chain length-dependent affinities of chloride ion with indolocarbazole foldamers $\mathbf{1 - 4}$, monomer to tetramer. The association constants were found to steadily rise from monomer $\mathbf{1}$ to dimer $\mathbf{2}$ to trimer $\mathbf{3}$, and then reached near saturation. In addition, we compared the binding affinities of chloride on between indolocarbazole trimer $\mathbf{3}$ and biindolyl trimer $\mathbf{5}$.

This paper is dedicated to Professor Eun Lee on the occasion of his honourable retirement.
Despite the same number of hydrogen bond donor NHs, 3 showed much stronger affinity than 5 by $\Delta \Delta G=3.2 \mathrm{kcal} / \mathrm{mol}$.

The synthesis of 1-4 were previously described (Scheme 1) and the association constants of $\mathbf{1}$ and $\mathbf{2}$ with chloride ion were reported to be $11 \mathrm{M}^{-1}$ for 1 and $560 \mathrm{M}^{-1}$ for 2 in a polar organic medium, 4:1 (v/v) DMSO- $d_{6} / \mathrm{MeOH}-d_{3}$ at $24 \pm 1$ ${ }^{\circ} \mathrm{C}$. ${ }^{5 \mathrm{a}}$ Unlike 1 and 2, ${ }^{1} \mathrm{H}-\mathrm{NMR}$ spectra of longer oligomers 3 and $\mathbf{4}$ were completely broadened out, thus giving no signal at all, possibly due to slow exchange between self-aggregates. However, addition of tetrabutylammonium chloride led to sharp and clearly resolved ${ }^{1} \mathrm{H}-\mathrm{NMR}$ signals corresponding to the chloride complexes of $\mathbf{3}$ and $\mathbf{4}$. The intensities of the ${ }^{1} \mathrm{H}-\mathrm{NMR}$ signals gradually increased and then saturated when one equivalent of chloride ion was added in deuterated acetone at room temperature, indicative of 1:1 complex formation which was also confirmed by Job's plots. The association constants of $\mathbf{3}$ and $\mathbf{4}$ with chloride ion were determined in fluorescence spectroscopy with excitation at $310 \mathrm{~nm}$ in $4: 1(\mathrm{v} / \mathrm{v})$ $\mathrm{DMSO} / \mathrm{MeOH}$ at $24 \pm 1{ }^{\circ} \mathrm{C}$. Upon addition of tetrabutylammonium chloride, the fluorescence intensity decreased up to I/ $\mathrm{I}_{0}=0.4$ and the wavelength was slightly red-shifted from 449 to $458 \mathrm{~nm}$, which has been commonly observed on the helical folding of aromatic foldamers. ${ }^{7}$ Nonlinear squares fitting ${ }^{8}$ of the titration curves yielded the association constants of 37,000 $\mathrm{M}^{-1}$ for 3 and $140,000 \mathrm{M}^{-1}$ for 4 .

A trend is apparent in the magnitude of the association constants (Figure 1). The binding energy $\left(\Delta G^{\circ}\right)$ steadily increases from monomer 1 to dimer $\mathbf{2}$, then trimer $\mathbf{3}$; one additional indolocarbazole unit enhances the binding affni-

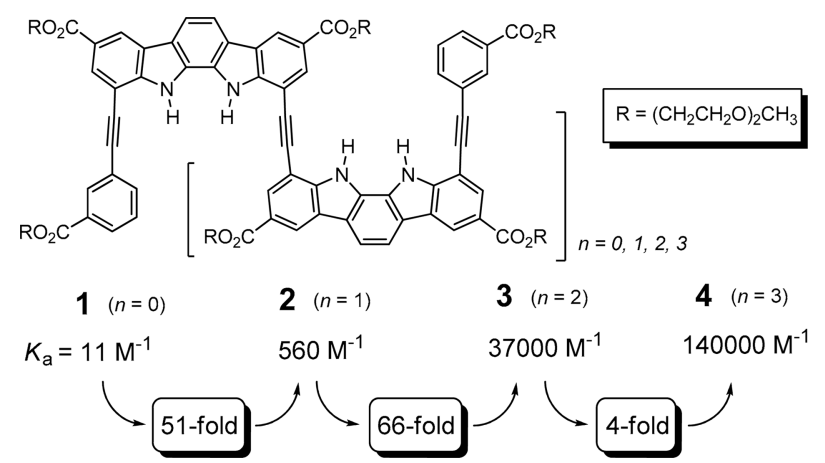

Scheme 1. Molecular structures of 1-4 and their binding constants with tetrabutylammonium chloride in 4:1 (v/v) DMSO/MeOH. 
ties by $2.4 \pm 0.1 \mathrm{kcal} / \mathrm{mol}$ under given conditions. However, the increment in the free energy is only $\Delta G=0.8 \mathrm{kcal} / \mathrm{mol}$ from trimer 3 to tetramer 4 , showing that one additional indolocarbazole unit in $\mathbf{4}$ does not participate effectively to the binding event. This explanation is also supported by computer models (MacroModel 9.1, MMFFs force field, gas phase). ${ }^{9}$ As shown in Figure 2, all of the six NHs in $\mathbf{3}$ are involved in strong hydrogen bonds with chloride ion $\left(\mathrm{NH} \cdot \bullet \cdot \mathrm{Cl}^{-}\right.$distances $2.5 \pm 0.2 \AA$ ). In tertamer 4 , however, six internal NHs form strong hydrogen bonds $(2.5 \pm 0.2 \AA)$ but two NHs at both ends are far away (3.1 $\AA$ ) for hydrogen bonds.

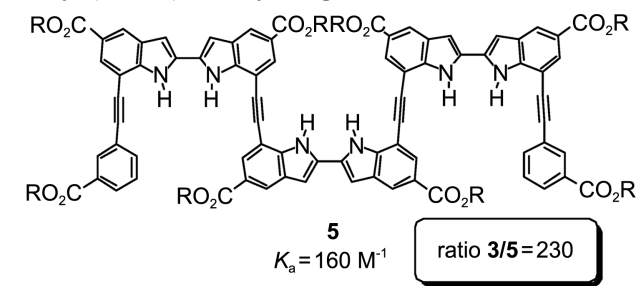

Next, we compared the binding affinity of chloride ion between indolocarbazole trimer 3 and biindolyl trimer $5^{10}$ in order to investigate the preorganization effect on the binding energy. It should be noted that two NHs in the indolocarbazole unit are fixed in a cis orientation but those in the biindolyl exist in a $s$-trans conformation to minimize dipoledipole repulsion. Upon binding chloride, the biindolyl moiety adopts an unfavorable $s$-cis conformation. This conformational reorganization should reduce the binding affinity. For quantitative analysis, we carried out ${ }^{1} \mathrm{H}-\mathrm{NMR}$ titration of biindolyl trimer 5 with tetrabutylammonium chloride in 4:1 (v/v) DMSO- $d_{6} / \mathrm{MeOH}-d_{3}$ at $24 \pm 1{ }^{\circ} \mathrm{C}$. The association constant was determined to be $160 \mathrm{M}^{-1}$ which is much smaller

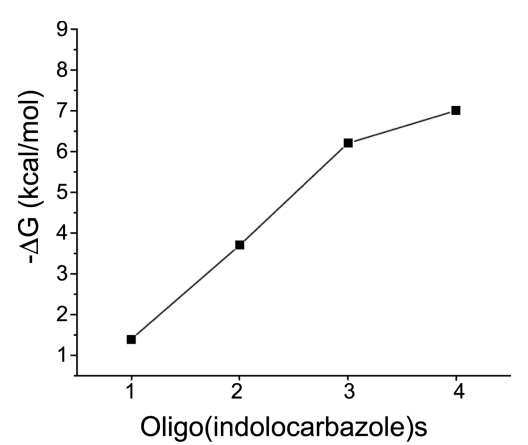

Figure 1. Plot of the binding free energy $(-\Delta \mathrm{G}, \mathrm{kcal} / \mathrm{mol})$ of $\mathbf{1 - 4}$ with chloride ion.
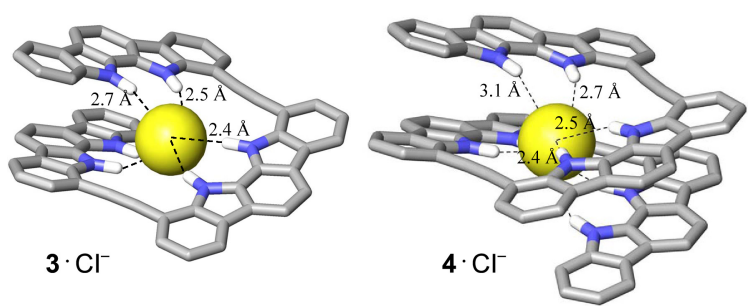

Figure 2. Energy-minimized structures of the chloride complexes of trimer 3 and tetramer 4 (MacroModel 9.1, MMFFs force field, gas phase). All of the $\mathrm{CH}$ hydrogen atoms, esters and phenylethynyl termini were omitted for clarity. than that $\left(37,000 \mathrm{M}^{-1}\right)$ of $\mathbf{3}$ and chloride ion. The difference in the binding free energy is $\Delta \Delta G=-3.2 \mathrm{kcal} / \mathrm{mol}$ which stems from the preorganization of indolocarbazole versus biindolyl.

In conclusion, we revealed the chain length-dependent affinities of chloride ion to indolocarbazole foldamers. Moreover, the preorganization effect on the stabilization of complexes was demonstrated by comparison of relative binding affinity of chloride ion between indolocarbazole and biindolyl trimers. Considering diversity of the length, size and shape, anions may display different selectivity on the chain length of foldamer-based anion receptors. We will continue our research in this direction.

Acknowledgments. This work was supported by the National Research Foundation of Korea (NRF) grant funded by the Korea government (MEST) (2010-0011075) and the Center for Bioactive Molecular Hybrids (CBMH). J.m.S. acknowledges the fellowship of the BK21 program from the Ministry of Education and Human Resources Development.

\section{References}

1. Comprehensive Supramolecular Chemistry; Lehn, J.-M., Chair Eds.; Atwood, J. L., Davies, J. E. D., MacNicol, D. D., Vogtle F., Exec. Eds., Pergamon: Oxford, UK, 1987-1996; Vols 1-11.

2. (a) Gellman, S. H. Acc. Chem. Res. 1998, 31, 173. (b) Gong, B. Chem. Eur. J. 2001, 7, 4336. (b) Hill, D. J.; Mio, M. J.; Prince, R. B.; Hughes, T. S.; Moore, J. S. Chem. Rev. 2001, 101, 3893. (c) Hecht, S., Huc, I. Eds.; Foldamers: Structure Properties and Applications; Wiley-VCH: Weinheim, Germany, 2007.

3. (a) Becerril, J.; Rodriguez, J. M.; Saraogi, I.; Hamilton, A. D. In Foldamers: Structure Properties and Applications; Hecht, S.; Huc, I., Eds; Foldamers: Structure Properties and Applications; Wiley-VCH: Weinheim, Germany, 2007; Chapter 7. (b) Juwarker, H.; Suk, J.-m.; Jeong, K.-S. Chem. Soc. Rev. 2009, 38, 3316. (c) Juwarker, H.; Jeong, K.-S. Chem. Soc. Rev. 2010, 39, 3664.

4. (a) Chang, K.-J.; Kang, B.-N.; Lee, M.-H.; Jeong, K.-S. J. Am. Chem. Soc. 2005, 127, 12214. (b) Naidu, V. R.; Kim, M. C.; Suk, J.-m.; Kim, H.-J.; Lee, M.; Sim, E.; Jeong, K.-S. Org. Lett. 2008, 10, 5373. (c) Kim, U.-I.; Suk, J.-m.; Naidu, V. R.; Jeong, K.-S. Chem. Eur. J. 2008, 14, 11406. (d) Naidu, V. R.; Suk, J.-m.; Lee, G. W.; Jeong, K.-S. Bull. Korean Chem. Soc. 2009, 30, 482.

5. (a) Suk, J.-m.; Jeong, K.-S. J. Am. Chem. Soc. 2008, 130, 11868. (b) Kim, J.-i.; Juwaker, H.; Liu, X.; Lah, M. S.; Jeong, K.-S. Chem. Commun. 2010, 46, 764.

6. (a) Tanatani, A.; Mio, M. J.; Moore, J. S. J. Am. Chem. Soc. 2001, 123, 1792. (b) Tanatani, A.; Hughes, T. S.; Moore, J. S. Angew. Chem. Int. Ed. 2002, 41, 325. (c) Nishinaga, T.; Tanatani, A.; Oh, K.; Moore, J. S. J. Am. Chem. Soc. 2002, 124, 5934.

7. (a) Prince, R. B.; Saven, J. G.; Wolynes, P. G.; Moore, J. S. J. Am. Chem. Soc. 1999, 121, 3114. (b) Zych, A. J.; Iverson, B. L. J. Am. Chem. Soc. 2000, 122, 8898. (c) Masu, H.; Sakai, M.; Kishikawa, K.; Yamamoto, M.; Yamaguchi, K.; Kohmoto, S. J. Org. Chem. 2005, 70, 1423 .

8. (a) Long, J. R.; Drago, R. S. J. Chem. Edu. 1982, 59, 1037. (b) Connors, K. A. Binding Constants; John Wiley \& Sons: New York, 1987.

9. (a) Mohamadi, F.; Richards, N. G. J.; Guida, W. C.; Liskamp, R.; Lipton, M.; Caufield, C.; Chang, G.; Hendrickson, T.; Still, W. C. J. Comp. Chem. 1990, 11, 440. (b) Halgren, T. A. J. Comp. Chem. 1996, 17,490 .

10. The synthesis and spectroscopic data of $\mathbf{5}$ were previously described in ref. $4 \mathrm{c}$. 